\title{
Tratamiento de la escala en el Moderno Racionalista y en el legado sui generis de Le Corbusier, principal fuente de la adopción iberoamericana del Estilo Nuevo
}

\author{
Treatment of scale in the Modern Rationalist Movement and the legacy of Le Corbusier \\ sui generis, principal source of the adoption of the new style in iberoamericana
}

$<$ Resumen>

El Movimiento Moderno Racionalista, adopta una postura sobre la «escala» que es distinta y distante a la visión decimonónica de Viollete le Duc. Se estudia en el presente trabajo las diferencias que al respecto tuvo Le Corbusier

The Modern Rationalist Movement adopts a distinct posture of uscale» that is distant from the nineteenth century vision held by Viollete le Duc.

This article discusses the differences that Le Corbusier had with regard to this.

<PALABRAS CLAVE>

MOVIMIENTO MODERNO RACIONALISTA / ESCALA ARQUITECTÓNICA / LE CORBUSIER / ARQUITECTURA LATINOAMERICANA

-KEYWORDS >

MODERN RAT IONALIST MOVEMENT / ARCHITECTURAL SCALE / LE CORBUSIER / LATIN AMERICAN ARCHITECTURE
Existirían tres maneras de analizar la escala arquitectónica y sus procesos. Un primer plano que indaga en las actividades mentales de inteligencia del espacio desde la dimensión físico biológica del ser humano -mecanismos de percepción e inferencia de dimensioneslas que se operan ante la necesidad de ponderar el lugar para actuar en consecuencia; un segundo plano, que considera los mecanismos de reacción fenoménica en estrecha dependencia de los caracteres y rasgos del propio estímulo -en nuestro caso, arquitectónico o urbano-, derivando de ellos una norma estadística con independencia de las capacidades del sujeto particular y herramientas hermenéuticas de que disponga y un tercer plano, que busca en ese nivel de conciencia que adjetiva el lugar como un todo coherente (epifenoménico). Si el primero y el tercer plano se sitúan en la propia naturaleza humana y en la dimensión existencial de un individuo que crea cultura y sistemas para entender el mundo, el segundo lleva a aquellos rasgos de las obras potencialmente capaces de promover cierto «escalaje» en determinadas circunstancias.

El Movimiento Moderno Racionalista (MMR) -al que adhirió la arquitectura occidental por dos tercios del siglo xx y que penetró con fuerza en países cuya cultura adoptada es exocéntrica-, concibió una sociedad que apostaría a la eficacia de la medida útil confiando en el resultado comunicativo que vendría por añadidura. Su expresión escalar no fue un propósito, y su estudio se ajustaría perfectamente al segundo de los tres planos de análisis: aquél centrado en los efectos de percepción dimensional ex post del propio estímulo.

Académica investigadora de la Facultad de Arquitectura y Urbanismo de la Universidad de Chile, es doctora en Arquitectura y Urbanismo de la Universidad Politécnica de Madrid. Autora de libros sobre visualidad, se ha especializado en pensamiento creativo. 
El «clasicismo» del Racionalismo: Leyes internas para aislarse del orden que intenta subvertir

El MMR resaltó una «composición» que privilegia la lectura desde leyes internas de edificio, sin buscar relaciones perceptuales que le conectaran a su entorno previendo, con tal autonomía, hacerlos más significantes de sus postulados ideológicos. Porque para revertir el orden imperante, se propuso negar validez a todo lo preexistente: con una plástica geométrica -simple y prestigiada antes en otras artes- e inexistente en la naturaleza, evitó toda asociación, dejando la decisión de dimensiones a condiciones funcionales y tecnológicas, favoreciendo la emergencia de una escala ad hoc inmanente de cada obra y hasta cierto punto «autista». De modo que apostando a una racionalidad inferente y conductual en el humano, que se activaría a partir del puro objeto, el MMR mantuvo explícita distancia respecto de los otros dos planos de actividad escalar: el de los mecanismos perceptuales de la visión implicante y el de la memoria situacional y significativa, al igual como se habían hecho autónomos y autorreferidos los edificios clásicos grecorromanos, cuyas interrelaciones internas eran obligadas e independientes de su tamaño.

\section{Razones del "autismo escalar» del Moderno Racionalista}

Varias razones históricas modelaron la expresión racionalista; pero las de mayor efecto escalar son tres y tienen origen en su método, en su extrema novedad y en su propósito redentorista:

- Primero: el hecho de que el MMR propiciaba un proceso proyectual fuertemente «deductivo»-que sintetizado postulaba «replantear las formas siguiendo la función de uso y las posibilidades de las nuevas técnicas con la geometría básica»- impulsó un «habla» formal para una coherencia desde la lógica occidental. Adoptando explícita indiferencia a otras presencias del contexto arquitectónico o natural, cohibió el ejercicio de actividades inferentes de la inteligencia visual: nivel de las relaciones que propicia el diálogo del objeto con el espacio inmediato de inserción. Fue tal la convicción ideológica del MMR respecto al Estilo Nuevo que, no importando dónde se implantara, las preexistencias urbanas -cualquiera fuese su carácter, historia, lenguaje estilístico, dimensiones y valor en la memoria social- no alteraron ni un ápice el proceso dimensional de los proyectistas, dejándose que operara el «tamaño» como simple resultante de una «escala funcional» -inexistente hasta entonces-.

- Además, el MMR confió que la capacidad visual captaría la naturaleza simple de sus elementos para inferir desde allí la naturaleza del total. Pero sería un reconocimiento difícil en las primeras obras dada su abstracción y ruptura de convenciones; aunque luego de "aprendida» la escala funcional facilitó procesos de «escalaje» específicos para diversos temas. Pero esa diferenciación, más allá del afán de romper con lo anterior, instó a imprimir una lógica a la producción buscando una eficiencia redentorista hacia un ser urbano tipificado. Debía ser aplicable universalmente anulando cualquier anclaje visual a rasgos locales, con el fin de promover la valoración del estilo nuevo que debía terminar por imponerse. La autorreferencia del repertorio formal y geométrico prefijado y segregante, explica que el MMR no se ocupara del nivel escalar relacional de sus formas en ningún escrito.

- En tercer lugar, debido a que el hombre destinatario del Estilo Nuevo era una representación idealizada, se le concibió como un ser ubicuo, no situado en determinado espacio geográfico. Si bien el MMR le entendía por primera vez como sujeto de derechos partícipe de grandes masas urbanas, lo asume con ejemplar y esquemático comportamiento gregario en los amplios espacios anónimos. Aunque recién es considerado en su dimensión funcional y biológica, cuyo raciocinio lo hace capaz de valorar abstracción visual, es sin embargo un ser privado de subjetividades, sin identidad. Ello explica que el MMR no se ocupase del plano expresivo informado por la memoria y el relato social.

Así, sólo en los atributos internos del objeto dan claves de la escala que alcanzaron de hecho los edificios racionalistas.

Pero en los cambios que en Latinoamérica intentaban oponerse a la herencia o a las expresiones importadas, si bien se vieron influenciados en general por los postulados europeos del Movimiento -más que por el desarrollo paralelo que experimentaba la corriente norteamericana-, quien tuvo la mayor influencia a partir de la década del '30, fue Jean-Edouard Jeanneret, bajo el seudónimo de Le Corbusier. Personaje paradigma, no sólo por sus postulados y la novedad atrevida de sus obras sino especialmente por su capacidad empeñosa en difundirlas. Quién, a las primeras directivas funcionalistas, a la depuración casi ética de las formas y a los conceptos técnicos innovadores, añade una audaz reflexión perceptual, más transformadora en lo arquitectónico y urbano, bajo explícitas premisas sociales que reformulaban todas las aristas de la vida en las ciudades. Su cruzada persuasiva tendrá gran éxito en las latitudes americanas por su aliento a emprender el «cambio necesario» que propaló personalmente en su visita a los países atlánticos del cono sur -invitado de Argentina, Brasil y Uruguay-; charlas que publica con su propio agenciamiento. Sus innovaciones llegaron paulatinamente a otros países con los viajes de académicos y arquitectos ${ }^{1}$.

\section{Adaptación y adopción del Moderno Racionalista en América Latina}

A juicio del teórico del racionalismo italiano Alberto Sartoris -no confundir con homónimos, y para quien la geografía es «el origen y villano del espíritu americano»-, la estética racionalista tuvo en el Nuevo Mundo la oportunidad de ejercitarse con menos inhibiciones, con una audacia y una madurez técnica ancestral muy manifiesta y un natural sentido estético. Esta arquitectura, más abierta y vidriada, se hace propicia al clima excepcional del continente y «ha alcanzado una personalidad y una interpretación de los temas que le son propias. Ha superado los peligros de la imitación»². Pero no hay que olvidar que Sartoris es un europeo de los años '50, época en que el MMR se había convencionalizado en Europa. Por eso no es extraño que quede desconcertado por la mayor irreverencia, especialmente en México y Brasil: «...rupturas intencionales de un orden que quisiéramos equilibrado y modular», aunque... «Ello no impide prever el importante porvenir

En Chile, los académicos cuyos viajes incidieron en la adopción del Estilo Nuevo, fueron en primera instancia los profesores de la Universidad de Chile Roberto Dávila Carson y Juan Martínez Gutiérrez. Dávila recomendaría posteriormente, en 1938, el viaje de Juan Borchers al Atelier de Le Corbusier, junto con otros tres estudiantes: Inés Frey, Pedro Letelier -mi padre-, y Santiago Aguirre.

Alberto Sartoris. Ordre et Climat Américains. En: Enciclopédie de L'Architecture Nouvelle. Tomo III. Milán: Editorial Stucchi, 1954. 
Fuente: Archivo personal Sofía Letelier.

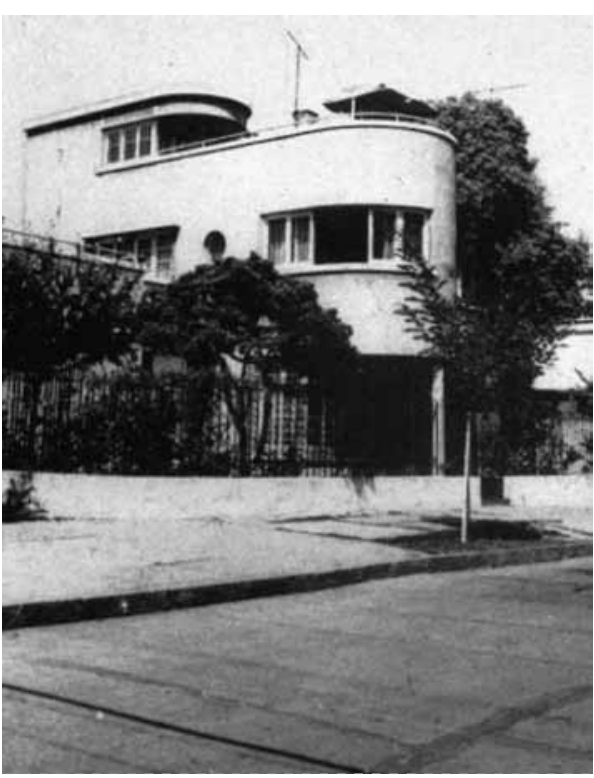

de estas estructuras significativas, donde el gusto por lo grandioso y el sentido constructor innato proclaman el espíritu original». Ve que las magnitudes del estilo en América se han modificado, aunque advierte zonas de América donde es posible diferenciar las adopciones del movimiento: «En el norte correspondiente a los Estados Unidos, la arquitectura nueva está más dedicada a edificios industriales y de oficinas (funcionales), mientras que en México ella se manifiesta civilmente en todos los dominios... Y en el sur, especialmente en Brasil, es de una sorprendente vitalidad y sobrepasa cuantitativamente a todos los países del mundo». Atenido a que en la buena expresión arquitectónica deben coexistir necesariamente cuatro condiciones -a saber: tradición local; nacional; universalidad; y espacialidad apropiada (por cultura, lugar, y posibilidad técnica)-, sostiene que en la versión del MMR de América del Sur se encuentran todas ellas equilibradas, augurando ya entonces que tendría un efecto de ida y vuelta.

\section{El legado escalar perceptual de Le Corbusier: "Veo, luego existo»}

Le Corbusier inicialmente abraza el Estilo por las promesas de cambio que sugería, y por la oportunidad de repensarlo todo que propiciaba. Pero, a diferencia de los racionalistas alemanes, no abdica de las tradicionales conceptualizaciones de la disciplina -como «la proporción», por ejemplosino que intenta re formularlas sobre nuevas
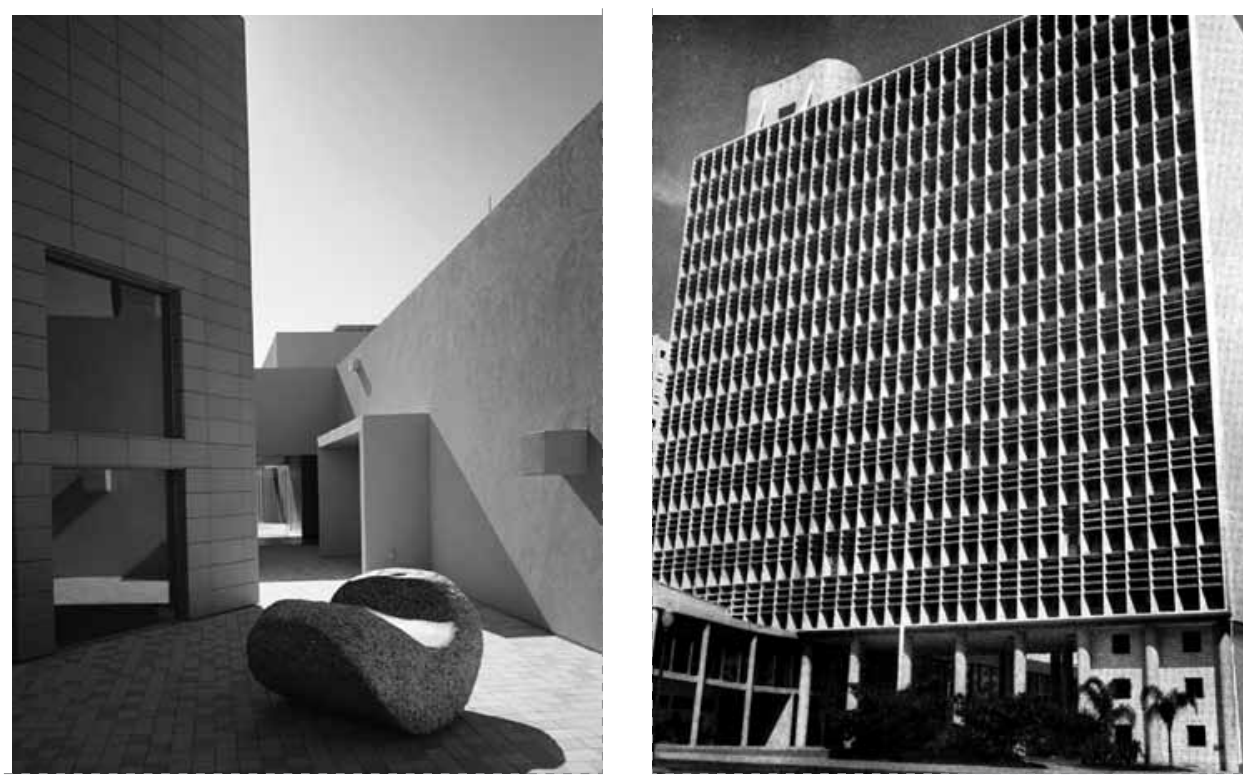

bases. Sorprende sin embargo que, a pesar de su preocupación por la proporción, y su cabal consciencia en tanto razón recursiva -en cuya búsqueda desarrolló series como el Modulor-, la escala, que se sabía indisoluble de la proporción desde Viollet-le-Duc, no fuese un tema en sus escritos: aunque manifiesta aisladas y agudas observaciones acerca de la «esquiva percepción de tamaños», la palabra «escala» es raramente mencionada, centrado más que en la percepción dimensional, en la capacidad de valorizar la corporeidad de la arquitectura. No obstante, es posible adivinar una implícita sensibilidad por las dimensiones de espacios y lugares, cuando indirectamente entrega claves de cómo ellas cuentan en sus pretensiones de que la arquitectura «no pase desapercibida».

\section{La escala en las "Precisiones» de Le Corbusier}

Apostando que habría indicios en las doctrinas de Le Corbusier que -por lo que sabemos hoyexplicarían la particular escala racionalista americana, nos remitimos a «Prècisions: sur un ètat présent de la architecture et de l'urbanisme»3, libro editado por él mismo en su primera edición. Allí, junto a sus impresiones sorprendidas ante las dimensiones de América del Sur -en el «Prólogo Americano» y en sus «corolarios» finales-, incluye sus 10 conferencias dictadas en Buenos Aires en
Fuente: Alberto Sartoris. Enciclopédie de I'Architecture Nouvelle. Tomo III. Milán: Editorial Stucchi, 1954.

1929 y los dibujos del rotafolio con que las ilustró frente al auditorio de académicos y estudiantes. Único libro entre su abundante producción -y una excepción entre los que difunden la doctrina de MMR-en que aparecen referencias directas e indirectas a los tres planos deducidos al inicio para el análisis de escala: hace constantes alusiones a la visión relativa del objeto, a sus relaciones internas y externas y, en menor medida, al plano subjetivo de la memoria. Además en esta obra hay algo que el autor no muestra en otras: su preocupación por la geografía -en este caso sudamericana-, y una extrema preocupación por los mecanismos visuales, aunque deducidos en forma intuitiva, escondidos bajo decires poéticos y en contenidos subjetivos; mientras aspectos doctrinarios y axiomáticos dan, para el lector atento, claves para alcanzar una escala propia.

a. Invocación a considerar la inmensidad de América.

La descripción de Le Corbusier acerca de la geografía de Sud América, invitando a «verla» como arquitecto, resulta fundamental. Las dimensiones extensas y la planicie infinita que observó en el borde atlántico; los colores intensos y contrastes, impactan su sensibilidad. Percibe a la Argentina desde un avión "verde y plana», a diferencia de Rio de Janeiro, «...rosa / rojo y verde/azul...». Mientras la luz y 

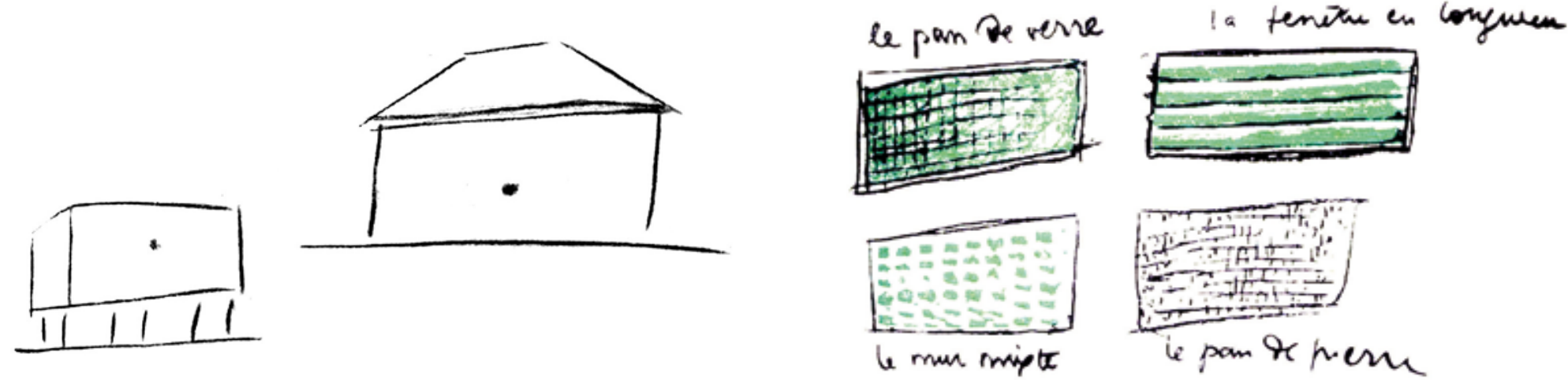

la sensualidad de las formas telúricas le sorprenden sobremanera en el Brasil costero, de Argentina lo remece esa inmensidad que se extiende: «Argentina está dimensionada para el avión; todo aquí es gigantesco.... Espectáculo cósmico que llama a la meditación... con su cielo ilimitado, que se extiende a los 4 horizontes. Todo el paisaje en una misma línea recta, el horizonte», dice conmovido, al sentir que abarca por primera vez la bóveda celeste completa y un «horizonte circular»; y los aislados asentamientos le indican las dificultades para emprender, todo lo cual reafirma su urgencia por convencer de las reformas urbanas que propugna.

En su primera conferencia en Buenos Aires, al llamar a los estudiantes a «liberarse de todo espíritu académico», aboga implícitamente por un nexo escalar con el entorno que el Estilo Nuevo no había propiciado. Observa que Buenos Aires, al solidificarse en manzanas idénticas a los surgidas en Europa con la expansión industrial a fines del siglo xIX, ha negado cinco elementos que le son propios; dos de los cuales le parecen hitos urbanos singulares y otros tres «atributos naturales para un destino prodigioso», dice imaginando una arquitectura percibida «en contraste con aquellos colosos», los cuales enumera:

- los gigantescos muelles,

- la vegetación natural exuberante, (y muy próxima o incorporada a la ciudad, lo cual también le impone),

- el cielo local, «que se percibe como bóveda completa»,
- el estuario «tan inmenso que se confunde con el mar»,

- la planicie «inconmensurable en la horizontalidad de la Pampa».

Reclama que no han sido suficientemente considerados como «la escena» que debiera hacer parte del todo arquitectónico. «Hasta ahora, los dos primeros han sido para la ciudad sólo elementos útiles; pero en el horizonte adquieren un orden propio, una belleza y una eficacia perceptual». Incita así a ser conscientes del contexto al generar la nueva arquitectura. $Y$ en su obsesiva preocupación por el Nuevo Estilo, no repara en que ya por entonces - década del 20- Buenos Aires exhibía tamaños perfectamente consonantes con la inmensidad en su arquitectura y urbanismo premodernos.

b. «Veo, luego existo»: Importancia de reflexionar la percepción.

A pesar de las escasas referencias que Le Corbusier dedica a la percepción como fenómeno interno del sujeto, la inmensidad de la Naturaleza de América le hacen cavilar con sentido filosófico: «Yo no existo en la vida sino por la condición de ver», reflexiona como arquitecto. Y, haciendo análogas la música y la arquitectura -porque ambas entregan al hombre mundos infinitos de alta complejidad mediante un solo sentido, una del oído y la otra de la vista-, piensa que en ellas el hombre se sublima en algo muy abstracto, que no es nada y es todo: la proporción. Desde su enfoque corpóreo de la arquitectura, ese algo tan relativo resulta primordial. «Saber ver la proporción es un 'estado de juicio', dice, anticipándose a teorías de inteligencia visual. Pero aceptando -como los arquitectos de la antigüedad- el necesario juego interno de proporciones para leer la arquitectura y valorarla, ellas no son para él independientes del entorno. Consciente -igual que Alberti- de que el de las referencias internas del objeto es sólo uno de los planos de la construcción escalar, deja los otros planos -el de relaciones externas y el de la formación del epifenómeno de significación- implícitos en su llamado a que percibir sea un acto reflexivo en el paisaje.

c. La técnica genera escala y determina una escala perceptiva.

De su conferencia «Las técnicas son la fuente del lirismo», emana la previsión de una «escala técnica» pero que va mucho más allá. Incitando a tener una mirada integrada de las cosas -incluso de las más prosaicas (la economía, la sociología, las técnicas) convencido de que serán fuente de belleza-, deja traslucir un primer indicio cierto sobre su comprensión perceptiva de la escala: al argumentar gráficamente las razones técnicas de las proporciones que asigna a sus inventos (los Pilotis, el Promenade sur le toit, las 4 fachadas, y la Planta Libre); y al justificar técnica y económicamente las ventanas horizontales «lado a lado», aporta cuatro observaciones de mecánica perceptual pura que incidirán en la escala posterior:

- Con el recurso de volúmenes sur Pilotis, busca que «suba el centro de gravedad de las masas». Al interpretarlo desde la visualidad, podemos suponer que refiere, no al hecho físico, sino a un correlato que intensifica la impresión de altura 
al sentirse más inestable el objeto, afectando su escalaje: resta "peso visual» al conjunto, porque mientras más alejada del plano de apoyo esté la centroide de gravedad, asumimos que tiene «menor peso» ${ }^{4}$, contra la atribución -significante- que se asocia a un volumen apoyado; se tiende a «contraer» visualmente el volumen elevado para alivianarlo por seguridad, porque la masa, sobre la extensión -por el «equivoco de Helmholzt»5- de los pilotes en la parte baja, adquiere liviandad, se enaltece.

- La ventanería «lado a lado», que había sido utilizada por Gropius y que Le Corbusier concibe funcionalmente complejas («el paño de vidrio fijo para fines de separar e iluminar y el batiente, a fin de ventilar; o, por privacidad, con celosías y bloques de vidrio»), confirió a los volúmenes una expresión de franjeados oscuros ininterrumpidos que, alternando con antepechos claros y regulares, provocan una mayor altura que la real, debido también a la llusión de Helmholzt.

- En cuanto a los paños traslúcidos de «bloques de vidrio», que utiliza profusamente, observa -esta vez explícitamente- que con ellos «la escala de la arquitectura se modifica», aunque sin explicar. Deducimos que tal modificación obedece a que la textura visual de los pans de verre, que al ser regular de cuadrados pequeños, engrandece por contraste a los elementos próximos y lisos que los limitan, mientras el patrón abstracto y homogéneo «impide» toda referencia a medidas ergonómicas del hombre, entregando una escala autónoma en su propia regla de medida y equívoca del total.

- Y ante la reducción de secciones que ofrece a la arquitectura el hormigón armado, Le Corbusier repara en la expectativa cultural: "Estos medios de composición quedan tan reducidos a 'O', que dirán ¿dónde queda la arquitectura?». Reducir la dimensión

\footnotetext{
4 Sofía Letelier, Francisco Brugnoli. Visualidad y
} neguentropía. Santiago: Editorial Universitaria, 2001. El equívoco refiere a que la percepción se expande en el sentido inverso al del franjeado, probado en 2 en el sentido inverso

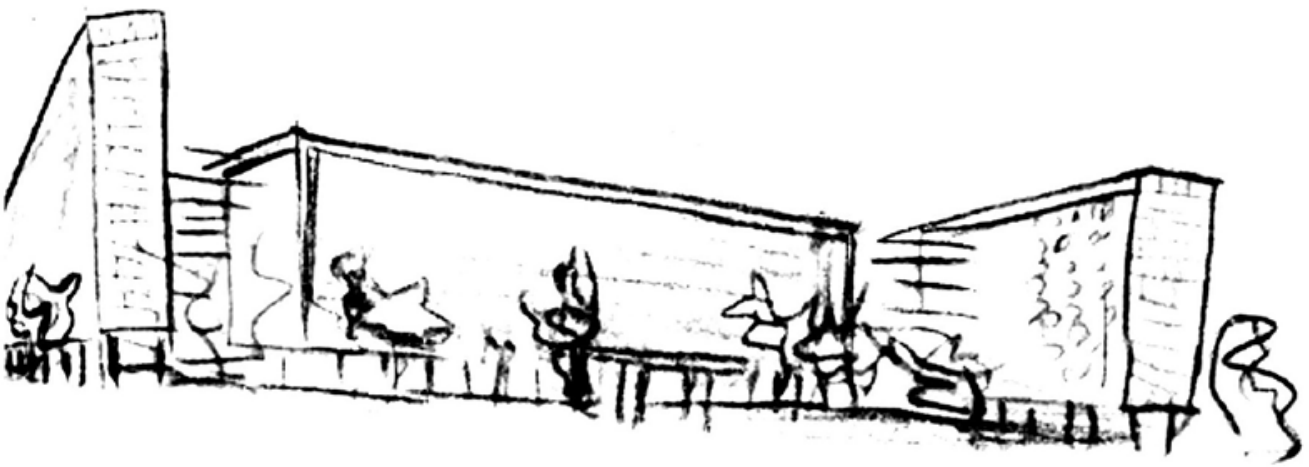

esperada cambió la escala a inferir desde elementos conocidos, los que por siglos de construcción en piedra entregaban un patrón de juicio de tamaños. El hormigón alteró además la ubicación de los elementos estructurales dentro del espacio, y con la «planta libre» se distancian y disminuyen en número. El patrón se había modificado totalmente.

Con estos cuatro recursos, el suizo proporciona claves que, o bien tienden a incrementar la altura percibida o la hacen ambigua e indeterminada para que se perciba más audaz de lo que es.

d. Aceptación y empleo del tamaño relativo de las cosas.

Los ejemplos de Racionalismo que Le Corbusier difundió en América, insistiendo en explorar las potencialidades del Hormigón Armado, extremaron la crisis de los modelos icónicos que el MMR había instalado. En su proyecto de tres cuerpos para el «Centro Soyus» de Moscú, utiliza en el cuerpo central por primera vez la idea de «volumen caja» con envolvente en un solo sentido, el vertical: deja las caras opuestas totalmente vidriadas entre flancos opacos, unidos por las losas. En éste explica con detalle haber utilizado un equívoco para obtener determinada percepción -de escala, aunque no lo reconoce-: «La dimensión (de los 3 prismas) aquí es fundamental en la composición: el central es 1 piso más bajo que los laterales»... Con ello logra -sabemos hoy- dar profundidad aparente al atrio que se forma entre los cuerpos y acentuar la "perspectiva», ya que el centro "se aleja», al verse (y ser) más pequeño. Logra así engañar en cuanto a la verdadera magnitud. $Y$ «para rematar la sinfonía arquitectónica aprovechando nuestros otros órganos de medida», incorpora una marquesina, que le sirve -justificándose en razones pragmáticas: para «amortiguar» el tráfico vehicular próximo-. Pero con ello en realidad da cuenta de estar muy consciente de que siempre anteponer algo pequeño dará majestuosidad o «grandiosidad» al volumen, mostrándose alerta a los mecanismos de contraste por significación.

e. Nueva escala por una diferente conquista de suelo para el «hombre nuevo».

\section{Una manera nueva de utilizar el} suelo urbano propugna Le Corbusier llamando a compensar la superficie de suelo edificado con la reposición del equivalente ocupado, proveyendo terrazas para la vegetación y disfrute a diversas alturas, para un futuro urbano de calidad. Y, si bien, muchas de sus propuestas como ésta fueron ensayadas con posterioridad, no se llevó nunca a la realidad el sorprendente tamaño con que él imaginó esas urbanizaciones. En su imagen mental -traducida en dibujos- se advierte una concepción de escala urbana implícita determinada por las unidades: «Edificios de 200 m de alto, que (si se cuenta el suelo que liberan los pilotis y el que aporta el promenade jardin sur le toit) ganan el 140\% de suelo», asegura; edificios que deberán estar «por orden y por arquitectura», dispuestos cada 400 $m$ de modo que se yerguen con "una dignidad emocionante, masa imponente de espacio y luz». Pero entremedio de estos edificios gigantescos, monótonos y geométricos -que por ello permitirían mensurar con facilidad las distancias intermedias brindando una percepción modulada del paisaje con una estricta pauta-, Corbu se permite introducir, con una libertad orgánica contrastante, onduladas vías y estacionamientos; flujos 
en meandros ${ }^{6}$ que hacen imposible su estimación dimensional; verdaderos «ríos de circulación, independientes de la habitación», en un suelo liberado por la suspensión de los volúmenes sobre pilotis. Ello dará, en tiempo y espacio, la nueva dimensión -en realidad «no medible»-al habitar urbano, que hasta entonces era dada por edificios bajos en subdivisión predial de $30 \mathrm{~m}$ de largo «como máximo», mientras en el futuro imaginado los más altos alcanzarían $160 \mathrm{~m}$ y los bajos y yacentes hasta $5 \mathrm{~km}$ de longitud.

En sus propuestas urbanas, no es que la «escala humana» -del hombre singularno esté presente, sino que la escala que imagina es definitivamente otra. Es la de un hombre gregario, alternativamente de paseo pedestre y motorizado. Que habita su privacidad en lo ortogonal y compacto, pero que dispone de espacios comunes libres de dirección y que ya no son intersticiales sino predominantes. La escala que podemos suponer a estos «espacios liberados» no responde a ningún patrón de escala urbana conocida, ni utiliza los referentes habituales de manzanas, anchos de calles, ritmos ni alturas continuas que permitan construir las redes de inducción heurística dimensional. El largo de algunos volúmenes $-5 \mathrm{~km}$ - no puede ya captarse y sólo es fuga, porque superan la capacidad de la visión lejana del horizonte -4,7 km-, además de evitar referentes por estar aislados, rodeados de vegetación y de cintas viales con curvaturas que impiden estimar medidas; ellos no caben en un golpe de vista. Trabaja un aislamiento que «condensa» los objetos.

Es a partir de una antiescala urbana de Le Corbusier -ya que evita toda referenciaque malos remedos dan como resultado esa esponjosa suburbia de América, que evita convenientemente ser medida.

Así denomina Le Corbusier a un esquema aprendido en la Naturaleza de Sud América, y que utiliza como término descriptivo posteriormente al momento de editar las conferencias en París. Esta «ley del meandro»-que ha observado desde el avión en los ríos de Argentina y que está en la base de su ciudad imaginaria-, la explica como una vía «torrente principal» que hace «loops» formados por el trayecto en pronunciado «bustrofedón», a tal punto que sus curvas casi vuelven a tocarse. Sugiere con ello un principio fractal: una agregación que tiene su propia fuerza y propósito. (Para Le Corbusier, las propias ideas durante la creación siguen la ley del meandro, con una conexión principal y desvíos que vuelven a ella. Retornos que alargan los recorridos con una geometría imponderable).

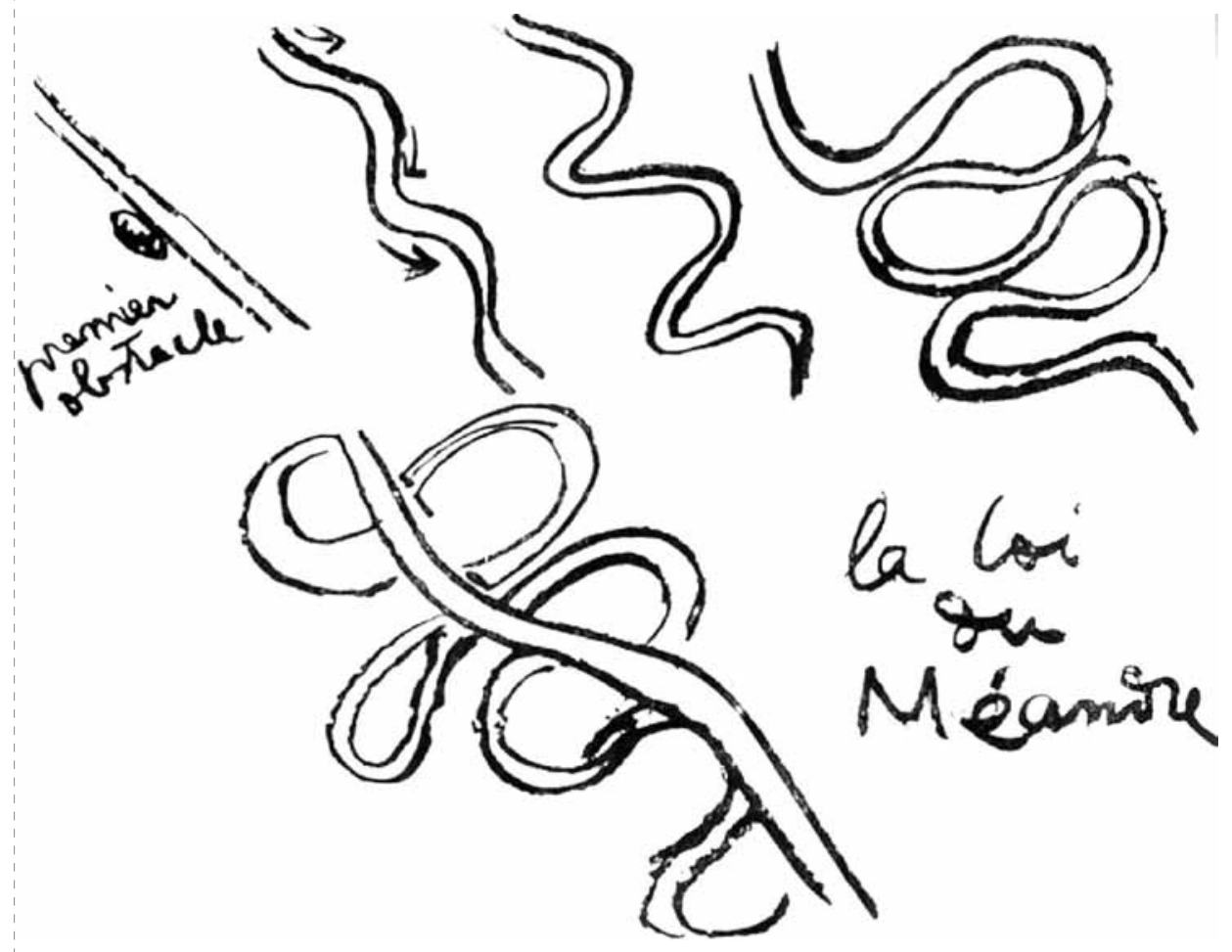

f. Una expresión autista.

Pero el urbanismo de Le Corbusier, no es una traza independiente de la arquitectura que se implanta en ella. Sólo es posible de la mano de «esa»

arquitectura, cuya «siembra» de prismas precisos establece el ritmo al que se adecuan libremente las vías, en un patrón nuevo: para seres dotados de una tecnología capaz de controlar y de superar las distancias e inconvenientes
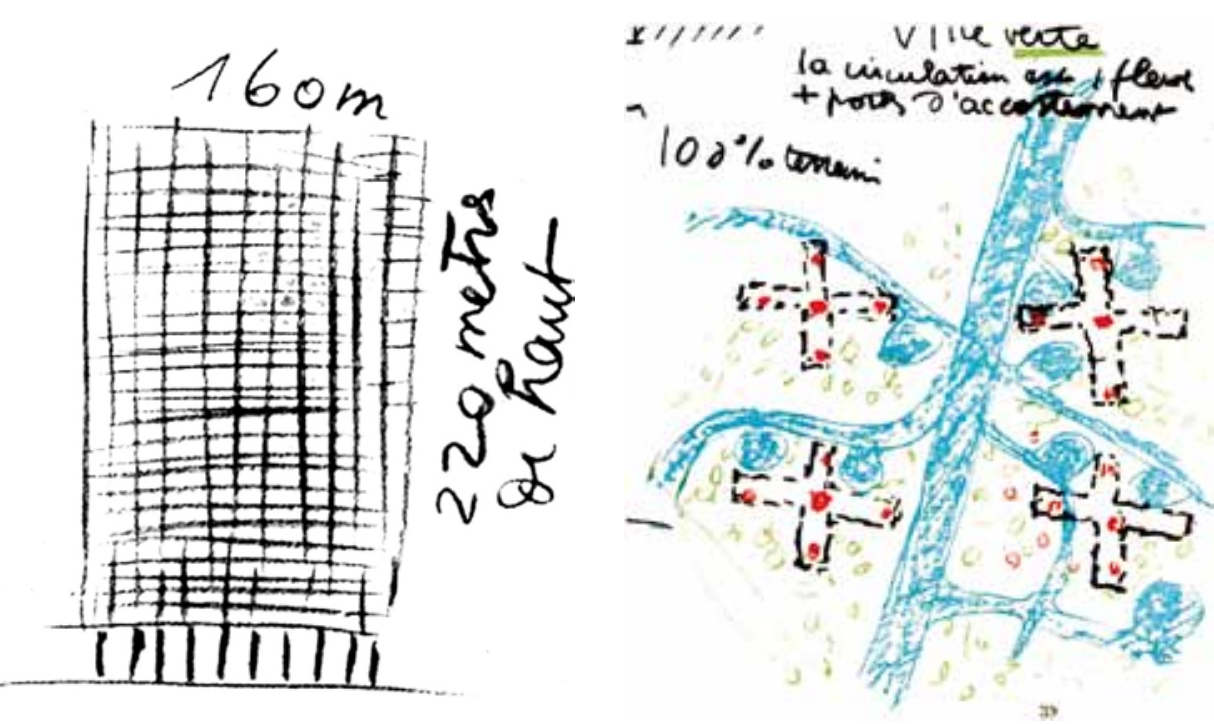
del clima, mientras disponen de acceso a múltiples servicios en edificios, cuya autonomía que proporciona la tecnología, pueden instalarse en cualquier parte. En forma contradictoria con la identidad que reclama para Buenos Aires -vaticina que «Estos edificios no tendrán expresión frente al clima local: serán (en todas partes) los mismos edificios de respiración exacta». Climatizados mediante esa doble piel con «muros neutralizantes»-, sus prismas constituirán luego el paradigma de los ideales de la arquitectura internacional. Pero andando el tiempo, ese modelo conceptual perdió toda sofisticación; y, con simplificaciones y reducciones de tamaño, su falta de identidad indujo una nueva tipología habitacional universal, el block, distinto a los «rascacielos» conocidos. Y aunque replicados a una escala urbana significativamente menor que la original, su racionalidad propició «siembras» regulares de bloques habitacionales para sectores sociales carenciados, con un distanciamiento apenas ajustado para permitir la ventilación y no interferir el asoleamiento. La tipología lisa y su laxa densidad volumétrica imprimió una escala común a los suburbios populares de cualquier ciudad.

\section{Claves escalares de la versión "perceptiva» de Le Corbusier}

A través de las premisas que a modo de axiomas Le Corbusier propala como la piedra angular de la apreciación arquitectónica, e origen y el rastro preciso de la escala que adquirieron las expresiones racionalistas en estas latitudes, se desprende de 12 aspectos entre los muchos que desarrolla, que-creemos- tuvieron mayor efecto en la indecible escala de nuestras ciudades ${ }^{7}$.

1. «Arquitectura es orden (ordenamiento)» y un continuo integrado con el urbanismo: Le Corbusier insiste de diversas formas en este concepto de orden -similar al de Louis Kahn- pero integrado. Pero si bien no define en qué consiste tal integración, es importante el hecho de que sitúa el goce arquitectónico no sólo en edificios, sino en las mutuas relaciones abstractas y multifactoriales de todas las cosas en lo urbano. E insinúa una apreciación "arquitectónica y urbana» del entorno geográfico, al decir que debemos leer la continuidad «en todo» lo que vemos.

7 Le Corbusier. «Précisions...». Op. cit.; pp. 72 a 85.
2. «La sensación arquitectónica surge por reacción a las cosas geométricas». Para Le Corbusier -que considera sólo la vertiente euclideana- «la geometría es propia del hombre»; "y por eso la arquitectura y las ciudades las hacemos geométricas», dice. Pero lo propiamente arquitectónico lo sitúa no en esa característica, sino en la reacción que ella suscita: supone que «la sensación arquitectónica surge por reacción a las cosas geométricas», aludiendo -como Boullée- a ese «algo» especial que emana de lo abstracto y perfecto. En el fenómeno arquitectónico, reconoce la existencia de una sensación que se transforma en cualidad -para nosotros Qualia con dimensión-, aceptando un fenómeno mayor que no es medible, como sí lo es la geometría que lo provoca.

3. La exageración de rasgos es CARÁCTER. En forma también similar al concepto que manejó en este sentido Boullée en el siglo XVIII, Le Corbusier observa que un prisma cuyas proporciones son «cotidianas y esperadas», parece anodino, mientras que al exagerar alguna de sus proporciones, logra sorprender. "La proporción determina siempre en algún sentido, independientemente del tratamiento posterior», y sería lo primero a decidir, porque el carácter es necesario. Si bien suena razonable la proporción promueve la identificación, pero no hace inferir el tamaño de la cosa: un tratamiento de texturas o de color, puede alterar la escala -dimensional y significativa-, y obviamente no ayuda al escalaje cuando son elementos desconocidos.

4. Efecto de vanos en la escala. Para los vanos rectangulares -propios de la arquitectura del MMR-sostiene que al perforar un prisma, creamos «nuevos lugares geométricos. Hemos definido los términos de una ecuación» que debe tender al equilibrio. Porque se forman «ejes» o líneas de relación, que responden a la visualización de «estructuras prolongadas». Ejemplifica gráficamente la red resultante (aunque sólo en arquitectura excepcional y en la suya propia): el prisma del Capitolio de Miguel Ángel y el prisma de la Ville a Garches. "Las diagonales de todos los rectángulos son perpendiculares entre sí», observa y repara en que allí «los anchos no son homogéneos sino casi áureos», dice (aproximando forzadamente a la serie de oro). De aquí deduce que la apertura de ventanas o vanos establece subáreas determinando «los tiempos de la arquitectura». Tiempos que intuimos de relaciones internas que, junto con otras externas, permiten el sistema escalar.

5. Vanos desde el interior, su efecto escalar en un recinto: observa Le Corbusier que la percepción de un espacio interior varía según cambia el punto en que ingresamos y el escorzo que se ofrece del espacio desde allí, por efecto de la luz:

- según la posición del vano (puerta entre un recinto y otro), «si desembocamos en un eje al centro del espacio o a un lado, la impresión de aquel será diferente». En el eje se nos brinda mejor la dimensión longitudinal pero no la transversal que se comprime con la simetría; y

- según «nos interpelen las superficies iluminadas, dependiendo de la ubicación y extensión de ventanas exteriores en relación a nuestro ingreso», variará la forma del espacio; porque los planos se expanden, contraen, adelantan o retroceden, e incluso "cambian» de forma, de rectos a curvos o su configuración, dependiendo de la distribución de la intensidad lumínica.

6. El tipo y carácter de líneas y formas inciden al apreciar la arquitectura (y su escala): Para Corbu, conocer el grado en que líneas y formas contribuyen a la mejor percepción, permite seleccionarlas y darles un orden. Sugiere el siguiente orden:

- Primero, decidir las rectas y las que están en ángulo recto ya que otorgan una nítida percepción;

- luego decidir otras, onduladas o quebradas;

- $y$-finalmente- las que tienen capacidad de determinar centros y de establecer cerramientos.

Tal orden resulta fundamental al «escalaje». Porque las rectas no sólo facilitan su prolongación relacional, sino que definen la pauta para la localización del núcleo de interés visual, sea del entorno y las cosas que lo pueblan. Las líneas onduladas o quebradas, en tanto, si se atienen a una única dirección, operan como rectas aunque agregan dinamismo deteniendo la fluidez visual. Mientras las líneas que tienden al cerramiento, convexas al observante o cóncavas que le incluyen, al inducir un foco ordenador y 
definir áreas distintas, permiten modular los lugares, y deducir las distancias entre el aquí, el allí y el allá.

7. El ángulo recto: «Es el lugar de todas las medidas», declara enfático Le Corbusier. «Potencia la síntesis», dice en forma abstracta. Pero apunta a la capacidad de precisar, de concentrar o de referir todo en un punto, lo que permite dar inicio a las referencias en el círculo que establecen dos ejes transversos, definiendo cuatro áreas colindantes que organizan y saturan el espacio. Deducimos que se refiere a ello cuando agrega: «....La vertical 'fija' el sentido de la horizontal. Una vive por la otra; extensión y altura en síntesis». Para efectos de escala y distinguiendo «escala horizontal» en la extensión, de una «escala vertical» para manifestar alturas -cada una de cuyas conceptualizaciones se infiere respecto de la otra-, el pensamiento cartesiano de la lógica occidental necesita de al menos dos ejes para entender el espacio, y el MMR con su ortogonalidad favoreció con Le Corbusier estas relaciones e inferencias escalares, a pesar que no se lo propuso.

8. La jerarquía que damos a las cosas, importa; no es sólo simbolismo. El hecho de que para la comprensión del mundo hacemos prevalecer lo esencial en el momento, es apenas tratado por Le Corbusier; pero nos basta su insinuación a apoyar la lectura arquitectónica, «jerarquizando» ciertos elementos. Insta a facilitar al sujeto la asignación de jerarquía, poniendo énfasis en aquello que deseamos opere como «primera percepción». Sabemos que ello resulta fundamental a la atribución de escala; no sólo porque la impresión dominante entrega el patrón base de referencia dimensional, sino porque aporta su contenido significativo como fuente de alusiones escalares y comparaciones.

9. «Tendencia del espíritu hacia lo simple, como juicio». Intuye Le Corbusier que debido a las complejidades del entorno, y tal vez para conjurarlas, el hombre inventó ese «estado de conciencia» que valora lo simple y simplifica para entender. Supone un «sistema espiritual» nacido del juego mismo de las formas que entregan sus estructuras como claves para operar; a lo que debe contribuir la arquitectura y no inhibirlo. La escala sería parte de este sistema de simplificación innato; no porque la escala sea -o resulte de- una «simplificación», sino porque la utiliza.

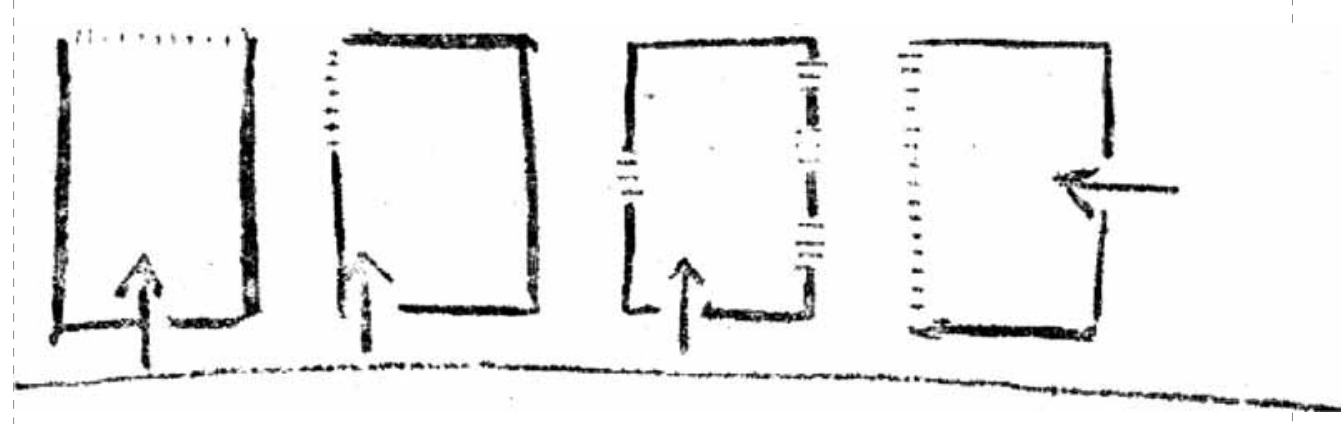

Y no es simplificación por cuanto agrega significado, sentido, relaciones y vínculos a aspectos muchas veces independientes o hasta no presentes; pero suma simplicidad al objeto al instar a percibir un conjunto variado y desconectado (la realidad) como «un todo», en la dimensión atribuida.

10. Lo simple, no equivale a «pobre». En su intento por defender lo escueto y los volúmenes desnudos que se bastan por sí mismos, Le Corbusier apuesta a que gratifican al compensarnos por su sola intensidad. Dice: «Es una opción (estética) que tiene por objeto la pureza misma. Es una concentración». Viendo las ciudades como sumatorias, formadas por cuerpos distintos, constituidos a su vez por agregación de cosas muy diversas, lo que entrega una silueta que es «tumulto y cacofonía» de motivos, intenta evitarlo con lo simple. Pero en esto se equivocaba: si ciertamente lo simple no es necesariamente pobre, la excesiva simplicidad, al tiempo que condensa, aísla el objeto al evitar relaciones externas; $y$ la ausencia de articuladores visuales, sin puntos que anclen la atención, produce ambigüedades escalares que, según estén manejadas, pueden tanto agregar tensión positiva como negativa, disconfort que interfiere con la formación de redes relacionales.

11. Simplicidad en las unidades y complejidad en el total. Advirtiendo lo anterior, no obstante que dice evitar la complejidad en las unidades, Corbu reserva la riqueza perceptiva para el total urbano, alerta a la necesidad de lo diverso: «La diversidad, indispensable a nuestro intelecto, la reservamos para cuando se presente la sinfonía de la ciudad, y en respuesta a los nuevos problemas del urbanismo moderno», que reclama nueva escala. $Y$ demuestra ser el gran innovador, al subvertir los postulados clásicos que admiraba, e incluso la primera ley de la Gestalt: llama a lograr «unidad» en los elementos y diversidad en el todo, invirtiendo aquello de obtener unidad en el total con variedad en las partes ${ }^{9}$. Obviando que hace equivaler complejidad y diversidad-aunque refieren, uno a las relaciones y el otro a los componentes-, para la escala resulta favorable tal inversión: para un observador, disponer en lo próximo de elementos simples que pueda desplegar como patrón dimensional, favorece la comprensibilidad del lugar en que está, provee una orientación referencial y un módulo, aspectos útiles para la interpretación escalar del entorno complejo. Y permite distinguir lo que «no es» artificio y asumir ese resto como «fondo» neutro. Cuando por el contrario, lo próximo es excesivamente complejo, independientemente del entorno que lo circunde se dificulta extraer claves de medida física y del espacio de referencia cognitivo para la atribución escalar -a lo inmediato y al resto-, aún cuando el lugar pueda producirnos sensaciones magníficas y mucha adrenalina.

12. El entorno hace parte del fenómeno arquitectónico y afecta a la percepción de escala. Finalmente, Le Corbusier se hace cargo explícito aquello que no había hecho el MMR. Observa que una misma cosa -por ejemplo, un cubo- puesto en paisajes distintos, varía porque «la armonía es un juego de todo con todo", sentencia, argumentando que no podemos sustraer la arquitectura del entorno, al cual comienza a pertenecer y a participar. Así podemos descubrir tesoros diversos cada vez en la misma arquitectura: «Estas realidades inmanentes estarán siempre presentes para aquel que sabe ver y que desea extraer su beneficio». Aunque su discurso 
N 0

de arquitectura

es filosófico, sus dibujos dejan enseñanzas tácitas que inferimos útiles para la percepción de escala:

a. En el horizonte y aislado, aunque se ve pequeño (la horizontal por contraste lo comprime en el ancho), el cubo gana importancia por su unicidad y densidad al concentrar la atención en él, (Ley de Ricci). Se ve potente, mientras la escala del paisaje, sin más referencias, se expande.

b. En posición transversal al fondo de una calle y enmarcado por edificios en perspectiva, el prisma se «agranda» debido a la «compresión» del marco: tiende a elevarse al ir «bajando» las líneas superiores que convergen en la virtual prolongación de las fugas, las cuales, generando ángulos hasta «más abajo» de una «línea de tierra» imaginaria, permiten por contraste aumentar su altura.

c. Instalado el prisma en forma simétrica ahora, al fondo y en el eje de una alameda, la sucesión de árboles que modulan la distancia «alejan» el prisma (efecto Helmholzt), magnificando su tamaño real: al «verse lejano» sin modificarse de veras, se aduce que el tamaño que percibimos «debe» ser grande si estando «tan lejos» se ve así.

De estas premisas, que luego precisa en 5 postulados proyectuales bien conocidos («especificación de las formas», «dimensionamiento funcional ajustado a lo útil», «circulación con patrón propio», «composición»y «proporción»), se constata que en la pureza conceptual y estética del racionalismo que Le Corbusier predica en América se fue determinando de partida una compleja forma de escalaje, pero que depende siempre del entorno y del territorio, lo cual había sido ajeno al MMR. Induce una arquitectura que, no obstante su racionalidad -o tal vez por ello mismo- inserta en trazados urbanos que confabulan contra las certezas perceptivas, terminará por alentar a las arquitecturas americanas a absorber los principios, pero imprimiéndoles la propia escala de su territorio, lo que resulta favorecido por la abstracción y la simplicidad.

Y en nuestras ciudades es la noción misma de «lo urbano» la que se pone en crisis. No sólo debido a nuestras debilidades específicas sino, especialmente, debido a la generalizada adopción -tal vez demasiado ingenua y rápida- de los postulados racionalistas a través del emocionado seguimiento al perceptivo Le le Dehous articongons yevars
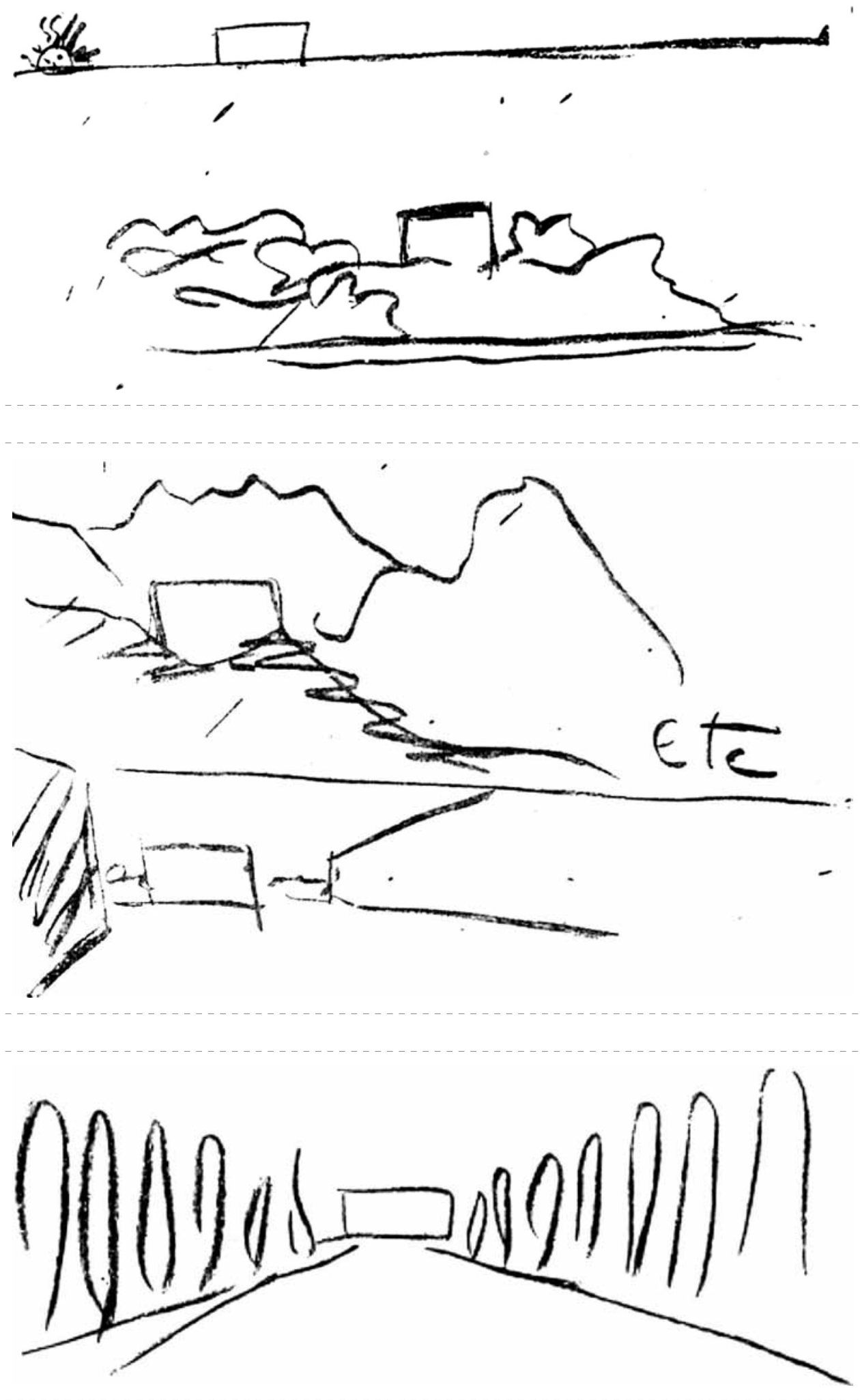
Corbusier. Porque si bien la adopción sumisa de sus postulados tuvo en América del Sur cuestionables efectos en la conformación y lectura de la ciudad del presente, facilitó sin embargo al mismo tiempo y debido a su misma abstracción y libertad, la posibilidad de despegarse de patrones heredados, de considerar el entorno y de explorar nuevas posibilidades -especialmente dimensionalesmás en consonancia con su realidad y con el sentido espacial que imponía su circunstancia geográfica surrealista.

Son precisamente las posibilidades contestatarias que ofreció el Movimiento Moderno Racionalista, pero en especial las provocadoras posturas de Le Corbusier con su mirada más perceptual y visual, que vibraba -más que en clave icónica de medidas- en una cuerda de proporciones expansivas y espaciales adaptable a cualquier envergadura, las que permitirán el salto hacia una identidad escalar propia con que se manifestó el Movimiento en cada espacio americano.

Consecuentemente, si al ser transplantado se produjo alguna «localización» escalar singular y consistente en el estilo -delatando la incidencia en ello de la geografía-, debiéramos buscar sus claves, no en las imágenes modélicas de las obras que establecieron la vanguardia en Europa, sino en aquellas ideas que lograron «de hecho» plasmarse en obras, reformuladas como efecto/afecto a su entorno en el Nuevo Mundo y que constituyeron, desfasadas en el tiempo, vanguardias locales.

\section{Referencias bibliográficas}

Philippe Boudon. Del Espacio Arquitectónico. Buenos Aires: Editorial Lerú, 1980.

Le Corbusier. Prècisions: Sur un ètat présent de la architecture et de l'urbanisme. Col. L'Esprit Nouveau. París: Ed. G. Cres et Cte, 1930.

Sofía Letelier, Francisco Brugnoli. Visualidad y neguentropía. Equilibrio visual. Santiago: Editorial Universitaria, 2001.

Alberto Sartoris. Ordre et Climat Américains. En: Enciclopédie de L'Architecture Nouvelle. Tomo III. Milán: Editorial Stucchi, 1954.

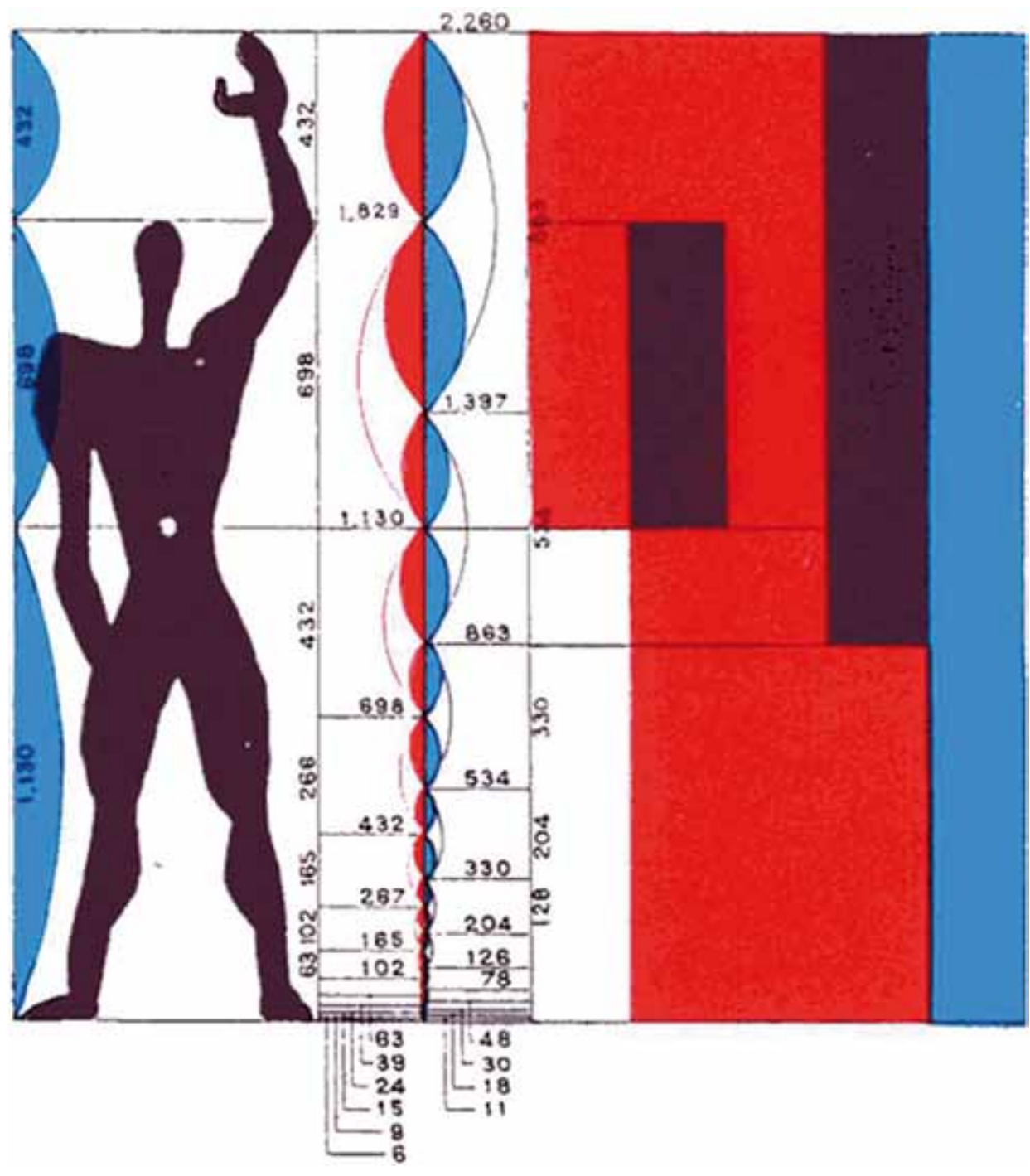

La fuente de las ilustraciones del artículo es Le Corbusier. Prècisions: Sur un ètat présent de la architecture et de l'urbanisme. Col. L'Esprit Nouveau. París: Ed. G. Cres et Cte, 1930. 